Meta

Journal des traducteurs

Translators' Journal

\title{
Plan-based Translation Assessment An Alternative to the Standard-based cut-the-feet-to-fit-the-shoes Style of Assessment
}

\section{Yong Zhong}

Volume 50, numéro 4, décembre 2005

Pour une traductologie proactive - Actes

For a Proactive Translatology - Proceedings

Por una traductología proactiva - Actas

URI : https://id.erudit.org/iderudit/019859ar

DOI : https://doi.org/10.7202/019859ar

Aller au sommaire du numéro

Éditeur(s)

Les Presses de l'Université de Montréal

ISSN

0026-0452 (imprimé)

1492-1421 (numérique)

Découvrir la revue

Citer cet article

Zhong, Y. (2005). Plan-based Translation Assessment An Alternative to the Standard-based cut-the-feet-to-fit-the-shoes Style of Assessment. Meta, 50(4).

https://doi.org/10.7202/019859ar
Résumé de l'article

La diversité des théories guide la pratique en traduction et en interprétation, et il en est ainsi de l'enseignement de la traduction et de l'interprétation mais dans de moindres proportions. L'évaluation pédagogique des traductions des étudiants se ramène à une catégorie qui s'appuie presque uniquement sur des standards imaginaires. Dans cet article, nous mettrons en lumière les caractéristiques d'un système d'évaluation qui se fonde sur une évaluation définie par une structure planifiée. La comparaison s'effectuera aussi sur le type d'évaluation proposé par les théories de la traduction fonctionnelle qui sont à l'origine de notre système d'évaluation. Nous conclurons avec une étude de cas utilisant la structure planifiée. 


\title{
Plan-based Translation Assessment An Alternative to the Standard-based cut-the-feet-to-fit-the- shoes Style of Assessment
}

\author{
YONGZHONG ${ }^{1}$ \\ Univeristy of New South Wales, Sydney, Australia \\ y.zhong@unsw.edu.au
}

\begin{abstract}
RÉSUMÉ
La diversité des théories guide la pratique en traduction et en interprétation, et il en est ainsi de l'enseignement de la traduction et de l'interprétation mais dans de moindres proportions. L'évaluation pédagogique des traductions des étudiants se ramène à une catégorie qui s'appuie presque uniquement sur des standards imaginaires. Dans cet article, nous mettrons en lumière les caractéristiques d'un système d'évaluation qui se fonde sur une évaluation définie par une structure planifiée. La comparaison s'effectuera aussi sur le type d'évaluation proposé par les théories de la traduction fonctionnelle qui sont à l'origine de notre système d'évaluation. Nous conclurons avec une étude de cas utilisant la structure planifiée.
\end{abstract}

\begin{abstract}
The practice of translation/interpreting is guided by a diversity of theories and so is the instruction of translation/interpreting, though arguably to a lesser extent. Yet, pedagogical assessment of translation, especially in relation to the assessment of translation works by students, mostly seem to fall into one kind, one which is overwhelmingly based on an imagined standard and concerned with accurate and adequate comformity to the standard.

The author of this paper, while experimenting with game theory and problem-based learning in the teaching of translation and interpreting, has been rethinking the assessment process. As a result, he has developed what he sees as an alternative system of marking, one which he calls planbased assessment and which aims to mark a student's work/performance against the specific plans formulated by the individual student in conjunction with the instructor rather than against the imagined singular homogeneous standard imposed by an authority. He believes that this system is more conducive than the conventional standard-based assessment to the teaching of translation/interpreting in liberal arts education as it facilitates the development of subjectivity, vision, different learning styles, creative/critical thinking power, and problem-identifying and -solving skills.

In this paper, he will discuss the characteristics of plan-based assessment system in comparison to those presumably comprising the conventional system. Comparison will also be made to the sort of assessment advocated by functional theories of translation as they inspired and informed the construction of plan-based assessment. The paper will conclude with a case study of the use of plan-based assessment.
\end{abstract}

MOTS-CLÉS/KEYWORDS

translation training, plan-based assessment, game theory \& game planning, functional theories, skopos

\section{Introduction}

There is a Chinese fable that goes like this: A man went to buy a pair of shoes for himself. Not knowing the size of his own feet, he bought the first pair recommended by the shop assistant and returned home. When he tried the shoes on his feet at home, they were found to be too small and hence a violent act was performed. That is, his feet were cut to fit the size of the shoes. A fable is a fable and the fate of the fabled feet does not have to be delved on now, but it left two marks of 
heritage. Firstly, it gave birth to a frequently quoted idiom in the Chinese language, xuezushilv (削 足适履), i.e., cutting one's feet to fit the size of the shoes. Secondly, it provided a starting and reference point for me to explore and now to discuss an alternative system of assessment, one that reverses the relationship between the shoe and the foot and aspires to facilitate the search for different shoes by different students.

In this paper, I will attempt to discuss this alternative system of assessment, which is named plan-based assessment and which has been theorised on the basis of my pedagogical experience and reflection. The concern of this system, as the forthcoming discussions aim to show, is overwhelmingly on the process and efforts taken by individual students of achieving the set objectives. I anticipate suspicion of some readers towards the validity of the system vis-à-vis practice of translation/interpreting by professionals. As much as I believe it is relevent to professional practice and can make us professionals reflect on how we can improve (assessment of) our own work, this paper is really about pedagogical assessment. By pedagogical assessment, I refer to evaluation of the performance by students of translation and interpreting, including both those aspiring to pursue a professional career and others wishing to learn it as general education.

This paper will start with a review of the current prevalent standard-based assessment system and funtionally based assessment system with a focus on those aspects that desire criticism and improvements. It will go on with an introduction to plan-based assessment, with a focus on its qualities that distinguish it from the other systems. There will then be a comparison of plan-based and other assessment systems. The paper with conclude with a case study of applying the system to the assessment of an actual translation assignment undertaken by three different students.

\section{Review of conventional assessment}

By conventional assessment, I refer to a whole range of systems of assessment characterised by a foremost concern with the standard and comformity to the standard. While there are undoubtedly many variants to what I categorise as the conventional system of marking, the following characteristics are recognisable to most of the translation/interpreting teachers in one form or another.

1. The assessment is standard based and there is usually a single homogeneous standard (or 'the' standard, to be more precise) and assessment is about measuring the closeness of a translation or otherwise to the standard.

2. The belief in the standard inherits the pre-Barthes presupposition of the essential and inherent meaning in the content and/or in the form of the text/author and the classical translation ideals of mirroring that meaning.

3. The closeness to the homogeneous standard is articulated in terms of accuracy and adequacy or lack thereof and hence we have a continuum that begins with the faithful translation on the one extreme and that degenerates towards a mistranslation on the other.

4. Any deviation from the homogeneous standard is met with deduction of marks and hence many instructors adopt a punitive system starting with one hundred marks and fixed quantities of marks are usually deducted for each instance of aberant interpretations, sentence patterns, choice of words and use of punctuations, etc.

5. The adoption of the the homogeneous standard assumes a final interpretative authority and that authority usually lies with the marker/teacher.

6. Attention is overwhelmingly paid to the end product and the process of translation is ignored, and 7. Great attention is given to students' capacities and resources to use the techniques acquired during the course to achieve accuracy and adequacy, such as appreciation of the standard, semantic or literal translation, dictionary skills and writing skills.

The emphasis on the standard reflects a lack of consideration given to the diverse cognitive capacities, language and cultural backgrounds and competences of the students. It also exhibits an obsession of measuring different students by the same standard. In other words, different 
students are forced into shoes of the same size and shape, a process that may be, from students' perspective, full of violence, pinches, pain and suffering. This makes the system unsuitable to modern classes that are getting increasingly larger and heterogeneous ${ }^{2}$.

The conventional marking system is most excessive in places where absolute respect to authority is the tradition or where the industry standard is adopted indiscriminately in teaching. Typical of the former is China where the teaching of translation/interpreting is tightly structured and often uses the same books, the same exercises, the same tests, the same solutions and the same assessment system. Typical of the latter is Australia, where the NAATI (i.e., the National Accreditation Authority for Translators and Interpreters) standard, together with its curriculum and test architecture (including test design, format, content and marking standard), is adopted in the teaching of translation and interpreting in universities ${ }^{3}$. In NAATI's Guidelines for Obtaining Approval of A Course in Interpreting/Translating (1998), there is a dedicated section of 'Marking Guidelines' which specifies in detail the categories of errors (e.g., general, isolated, repetitive), the gravity of the errors, the mark deduction for each type of errors and penalty for repeated errors. The section also foregrounds the sense of 'penalty', as apparent in the following quotation:

Errors consisting of incorrect rendering of the original, which seriously distort its meaning and affect the explicit or implicit meaning of the whole sentence or paragraph, should be penalised by the deduction of between 3 and 5 marks, or even more depending on the gravity of the error in the context, and the proportion of the passage distorted.

(NAATI 1991, p. 48)

What I see is a modern paradox: while we teachers of liberal education supposedly enjoin students to love themselves, to nurture their egos and to develop creativity, we measure their success in the internalisation of the homogeneous standard and in pain. The pedagogical ideals, such as those espousing creativity, interaction, personality development, generation and dynamic use of knowledge, are submerged in the mystique and discourse of accuracy and adquacy that are voluntarily or involuntarily imposed onto the students.

\section{Review of functionally-based marking}

Functional theories, which had been intended for 'systematizing the assessment of translations' (Munday 2001, p. 73), enlightened me in the search for an alternative assessment system. Reiss and Vermeer (1984), the pioneers of functional theorists, sought equivalence and coherence at the level of the text, which Reiss (1998) classified into three types: expressive, informative and operative and to Nord (1997) added a fourth, i.e., 'phatic'. As there were different types of texts, the functional theories of translation argued, there should be different and specific translation methods for each text type and the target text (TT) should transmit the specific function of a source text (ST). Thus, Reiss said that 'the transmission of the predominant function of the ST is the determining factor by which the TT is judged' (1989, p. 109). (I underlined the word judged to invite attention to the aim of Reiss' functional theory, which was about assessing translations.) Then Skopos theory of translation, with an even clearer sense of the purpose of a translation and of the act of translating, became aware of the person who did the action of translating and his/her intention for doing the translation, though the translator was assumed to be a fully trained and infallible professional. This budding awareness of the translator and the intention of the translation, which had the potential of subverting the legitimate status of the single SHOE, opened my vision to the physiological, psychological and emotional condition of the person who is to wear the shoes, i.e., the size, shape, need, expectations, history, etcetera of the feet. That is, literally speaking, the 'calibre' of the feet.

To continue with the metaphor of the shoe and feet, if the conventional assessment had the same shoe to force many different feet into, the functional theories of translation conceptualized different types of shoes according to the purposes, even though the sizes, shapes and other physical 
qualities of the feet continued to be unaccounted for. To name some of the types, there were now shoes to wear, descriptively speaking, for business (i.e., leather shoes), for decoration (fashion shoes), for trekking and horse riding (boots), for sports (i.e., sports shoes) and for beach walking (i.e., sandals). In the spirit of functional theories, whether a pair of shoes is suitable depends on whether one gets the sort of shoes that functions for him/her and fulfils his/her needs. It is no point getting a pair of soccer shoes for someone who is to go to a formal business meeting.

However, the attention paid to the translators as imperfect individuals was rather limited in functionalist theories, which were intended for assessing the works of fully trained translators rather than trainee translators as in my pedagogical situation. For one thing, whether the physical qualities of the shoes fit the feet of the particular person remained to be an irrelevant issue. For another, there is no account for (or seemingly could not be bothered about) the intra-type differences including, for example, soccer shoes, basketball shoes and joggers in the category of sports shoes

\section{Plan-based assessment}

If conventional standard-based assessment had the single shoe to fit all the feet into, if functional theories replaced the single shoe with many different types of shoes to suit the many different purposes for which shoes were worn, what I have experimented with and propose now in this paper is an alternative system of assessment which evaluates the shoes bought by a person on their suitability to his/her feet and his/her efforts in acquiring the shoes. This option, which I would like to call plan-based assessment, requires an individual to work out a plan for tackling the translation, to implement the plan, to improve the plan while executing it and to improve his/her translation expertise at the same time as the plan being executed. Furthermore, the person must also justify the plan's validity/viability before actually proceeding to execute it.

To again use the acquisition of shoes as an analogy, a sensible assessment of an acquisition should ideally require the shoe buyer to have a sound knowledge about own feet, to conduct necessary market research, to work out an acquisition plan on the basis of the foot knowledge and market research, and to justify the acquisition plan. He/she must then make efforts to implement the plan. That is, he/she must specify what shoes (i.e., type, colour, shape, etc.) he/she intends to acquire for what purposes at what cost and how he/she intends to acquire the shoes effectively (e.g., purchase in person, by mail, on the Internet or by private sale). $\mathrm{He} / \mathrm{she}$ must also justify the plan on the basis of research. For example, that the shoes to be bought are indeed the ones that fit his/her feet, purposes, preference and also the social norms and represent the best value for the price paid, that the strategies for buying the shoes are effective (i.e., not too risky or costly or uncomfortable) and that the plan is viable (i.e., manageable and not too costly or risky). Next, he/she must attempt to implement the plan, i.e., actually buying the shoes by the means specified in the plan. What the assessor does is reviewing the plan and assessing the shoe buyer's actual process of buying the shoes as well as evaluating the shoes bought.

That is, when buying shoes, a plan-based acquisition plan looks at the acquisition as a process wrought with all sorts of possibilities, which may seem to be unnecessarily bookish and academic. But I believe that it is essential for a fulfilled experience of shoe hunting. Likewise, in assessing translation, plan-based assessment looks beyond the result of translation, i.e., not just the translator's reading and representation of the ST. It expands the scope of assessment from the result to the process leading to the end result, i.e., the whole range of activities in the pre-translation preparation and the actual act of translating, including researching, planning, implementing the plan, managing costs/risks, identifying problems and formulating solutions. I 
am happy to add that not only general language educators but also translation educators, e.g., Lee-Jahnke (2005), are directing more and more attention to teaching as a process of studentcentred learning.

This expanded process of learning enables assessors of translation to see the following questions:

1. Is there a plan for tackling the translation?

2. Is the plan based on research of the market and the resources available and on a sound knowledge of the expertise and weakness of the self?

3. Does the plan, on the basis of the research, specify objectives (i.e., for whom, for what purposes, etc.) for the translation to achieve, demonstrate a clear estimate of the problems that may hamper achievement of the objectives and have problem-based strategies/solutions?

4. Does the plan show an awareness of the costs and risks associated with the objectives and the strategies and whether the plan has the resources to manage the costs and risks?

5. Is the plan, including especially its objectives, justifiable in terms of viability and ethics, or is it suitable in conjunction with the strengths (and weaknesses) of the translator and with the intention/type of the source text and source author?

6. Has the translator been able to implement the plan, to adjust it where there was the need to do so, to utilize the resources efficiently, to identify/solve the problems and to achieve the specified objectives?

7. How close, as the assessor sees it, is the end result to the professional standard and practice (which is one of the many concerns of the assessor)?

There are many important qualities that distinguish plan-based assessment from the standard-based and functionally based assessment. The previously discussed attention to the process of translation rather than the end product is one of them. A second is the endeavour to evaluate a translation against the objectives individually selected and set by the particular author of that translation rather than against the imagined universal standard as in the standard-based assessment or the typologically based standard as in the functionally based assessment. That is, in plan-based assessment, the construction of objectives is personalised, decentralized and entrusted to the individual students. Whatever objective is selected and adopted for a translation task-even if this is done by the student him/herself, the marking of that task should endeavour to evaluate the achievement of that objective rather than any other objectives, including the ones that embody the standard/principle of the marker or any other authority, even if this may lead to the disengagement from conventional discursive concepts such as accuracy. So, for example if a personally selected objective is to deliver a rendition that is close to the target readers of the TT and friendly to readers who are less educated, uninformed about and unsympathetic to the cause of the ST, the achievement of that objective rather than any other ones should be the overwhelmingly foremost consideration in the marking.

A third distinguishing quality is the treatment of translation as an economical process of management rather than simple cross-language translation. Ideally, plan-based assessment is concerned not only with whether a student can achieve his/her own nominated objectives with a translation assignment but also how he/she does it. It examines how an individual student sets his/her objectives, how he/she identifies problems and works out solutions, and how he/she controls and minimizes costs and risks in order to optimize the results of the translation. All these, which transcend 'accuracy', 'adequacy', 'equivalence' and many other existing translational concepts, fall into what is known as 'management' in economics and game theory.

A fourth distinguishing quality is the recognition of and respect for personal differences and for individual students' intellectual aspirations and capacities to conduct research, identify problems and formulate solutions in different manners, to develop different translation strategies 
and to develop different working styles. Compared to those assessment approaches that measure end product by the same standard, plan-based assessment evaluates progress as well as competence, dynamic application of knowledge as well as knowledge, and utilization of personal strength and avoidance of personal weakness as well as strength (weakness). It is especially useful for assessing individual students' resourcefulness (including abilities to conduct research, to plan and to implement the plan) as it motivates them to understand own resources, to better utilize their different resources in order to achieve the selected objectives and to manage personalised problems, costs and risks. Hence, it has greater potentials for creating space for students to specify different objectives, to manage different sets of problems and to formulate different strategies on the basis of different sociolinguistics backgrounds. Furthermore, it can motivate trainee translators to develop new resources. In my experiences, it is also a more equitable assessment methodology for a heterogeneous class in terms of aspirations, sexes, ages, work experiences, specialisations and sociolinguistic backgrounds.

To sum up, plan-based assessment is characterised by attention to the process of translation, personalisation/decentralisation of objectives, treatment of translation as an economical management process and respect for individuality. These qualities, by viewing the learning of translation as a continuous dynamic process, make plan-based assessment different from all other assessment methodologies that foreground the standard and the end product. They transform translation (and its learning) into a game-like process ${ }^{4}$ where, in addition to putting up to peer rivals, individuals are challenged to utilize their own intellectual capacities, to continuously enhance those capacities, to take responsibilities for their own actions and to justify their own decisions. In my own pedagogical assessment experiences, they also facilitate a shift from the punitive system (i.e., deduction of marks for deviations from the standard) to a system that encourages students' self motivation and self challenges, which has proved empowering to my students.

To conclude the discussion of plan-based assessment, I have tabled a list of the differences between conventional assessment, functional-based assessment and plan-based assessment.

Table 1: differences between conventional, functionally based and plan-based assessment

\begin{tabular}{|c|c|c|c|}
\hline & Conventional & Functional & Plan-based \\
\hline $\begin{array}{l}\text { Standard of } \\
\text { translation }\end{array}$ & $\begin{array}{l}\text { Singular \& } \\
\text { homogeneous }\end{array}$ & $\begin{array}{l}\text { Plural and diverse, } \\
\text { and genre-based }\end{array}$ & $\begin{array}{l}\text { Individualised and } \\
\text { personalised based }\end{array}$ \\
\hline Test scope & Result of translation & Result of translation & $\begin{array}{l}\text { Process of translation, } \\
\text { management skills and } \\
\text { progress of trainee }\end{array}$ \\
\hline Equivalence & $\begin{array}{l}\text { Of foremost } \\
\text { importance }\end{array}$ & At text level only & Not a major concern \\
\hline Test objectives & $\begin{array}{l}\text { Achievement of } \\
\text { accuracy and } \\
\text { adequacy }\end{array}$ & $\begin{array}{l}\text { Achievement of } \\
\text { type-specific } \\
\text { accuracy \& } \\
\text { adequacy }\end{array}$ & $\begin{array}{l}\text { Achievement of } \\
\text { students' own } \\
\text { objectives \& } \\
\text { advancement of the self }\end{array}$ \\
\hline $\begin{array}{l}\text { Skills to be } \\
\text { tested }\end{array}$ & $\begin{array}{l}\text { Use of techniques to } \\
\text { meet standard }\end{array}$ & $\begin{array}{l}\text { Use of techniques to } \\
\text { meet intra-typical } \\
\text { standard }\end{array}$ & $\begin{array}{l}\text { Management of } \\
\text { resources, risks and } \\
\text { costs to achieve set } \\
\text { objectives }\end{array}$ \\
\hline $\begin{array}{l}\text { Making of } \\
\text { meaning }\end{array}$ & $\begin{array}{l}\text { Text and authored } \\
\text { centered }\end{array}$ & $\begin{array}{l}\text { Text, author and } \\
\text { function centred }\end{array}$ & Student centred \\
\hline $\begin{array}{l}\text { Psychological } \\
\text { impact of test }\end{array}$ & Punitive & Punitive (mildly) & $\begin{array}{l}\text { Encouraging } \\
\text { individuality \& } \\
\text { Empowering }\end{array}$ \\
\hline
\end{tabular}




\section{Case Study}

Next, I will present a case study of how I used plan-based assessment in a written translation assignment. The assignment was administered in an undergraduate class of Chinese-English translation at the University of New South Wales in the second half of 2004, involving 29 students of different sociolinguistic and academic backgrounds. They included international students from PR China, Taiwan, Hong Kong and Singapore as well as local students of both Caucasian and Asian backgrounds. Some of the students majored in arts and social sciences and others majored in natural sciences, engineering, medicine or law and took the course as an elective or general education subject. To cater for the diversity of backgrounds, expertises, needs and expectations, the course was intended to be of liberal education rather than specialised translation training. But there were quite a few in the class, including two of the three students featured in the case study, who aspired to be professional translators/interpreters or to develop a career that would incorporate translation/interpreting as part of the professional portfolio.

I have chosen the three students for this case study because their performance provided convenient entry points for my discussion. As different individuals with different capacities, they tackled the assignment differently, set different objectives, encountered different difficulties, adopted different strategies, produced different renditions and, naturally, I assessed them differently. Of the three, the two students who contemplated a career that uses their Chinese-English proficiency were known as Students A and B in this case study. Student C, born in Singapore but having resided in Sydney for over 10 years, had retired and intended to seek a teaching position in China. Student A, an international student also from Singapore, had very limited resources especially in terms of academic English ${ }^{5}$ and professional experience. Student B, a Caucasian Australian, was a native speaker/writer of English but had very low Chinese competence. Student C was especially competent in academic and legal English and was very knowledgeable and informed in terms of professional and cultural capital.

The assignment, a Chinese insurance text of about 400 words to be translated into English, was given to the students at the end of an afternoon class and was required to be completed and emailed by attachment to me the instructor within 24 hours. The students were told that, as usual, the plan they were to implement and submit, including the specification of the objectives and then the achievement of the objectives, was as important as if not more important than the actual translation that they would submit for assessment. So the students were asked to first state a brief plan in the answer sheet, which specified whom they assumed the readers to be, what objectives they wanted to achieve with the translation, what they would do to achieve the objectives and how they intended to utilize their own resources. I quote the Objective Statements made by the three students:

Student A: I assume the reader of my translation to be an employer. This is because I am a beginning translator and, to get my first job, I must let a prospective employer know that I have the basic skills required of a translator and also I know how to avoid my weakness. Most important of all, I must make the English flow and minimize mistakes, especially grammatical ones, assuming the employer is a mono-lingual English reader.

Student B: As this text is a general introduction to the topic and thus applicable to a wide Australian expatriates (sic.) living in a big Chinese city like Beijing, the objective of the translation is to make it appear as if the original text was written in English; rendering it as simple to read and understand as possible.

Student C: Who would read a translation of an insurance literature from Chinese into English? Assuming that insurance is a more sophisticated industry in English speaking countries than in China, the text would only need translating into English when it is involved in a legal dispute and ought to be presented to insurance professionals or even lawyers for legal advice. So I must present an accurate, literal translation written in formal English with the sort of jargons used in the industry. 
Reviewing the plan formed part of the assessment of the translation assignment, as explained previously. While respecting the plans submitted by the three students, I set out to evaluate if the plans were justifiable and if they were actually implemented in the translation. I like especially the plans drafted by $\mathrm{A}$ and $\mathrm{C}$, but would not have responded so favourably if $\mathrm{C}$ had adopted A's plan or vice versa, as A's plan would have been a soft option for C and C's plan would have been too ambitious for A. By comparison, the plan formulated by B is harder to justify, which I pointed out to the student in my comments. Insurance is an aspect of the sort of modern life which Australian are familiar with and which requires extremely precise wording and phrasing and, presumably, most Australians expatriates living in Beijing and needing the kind of insurance are likely to be educated enough not to warrant the production of a simple translation.

Another consideration that I had when marking the three translations was whether each of them exhibited evidences of its translators having accomplished the plan, having made efforts to implement the plan and having utilized available resources or developed new resources. To do so, I checked each translation against the plan set for it respectively to see if the plan was implemented and, more importantly, especially if the objectives were achieved effectively and how this was done.

In the light of plan-based assessment, both $\mathrm{A}$ and $\mathrm{C}$ made a good action plan for the assignment and their renditions obviously achieved the objectives effectively. Student A produced a translation rendered in plain and smooth English with few difficult jargons and avoided making big mistakes and, by doing so, would comfortably impress a prospective employer as a good candidate for a translator's position. Where she used words not consistent with her objectives, I marked them out in my comments. Student $\mathrm{C}$ produced a rather accurate, literal translation rendered in more sophisticated English with many professional jargons, which would seem to be professional to his target readers. Judging that they both completed their plans and believing that they both made efforts towards achieving the respective objectives, I decided to view their translations as almost equally successful. If I had adopted a standard-based assessment system, I would have evaluated C's translation as much better than both A's and B's.

By comparison, Student B's plan, which I judged to be less justifiable, was not executed effectively. Student B had stated that his objective was to render the translation 'as simple to read and understand as possible'. But his rendition appeared to be baffling, self-contradictory and anti-commonsensical in quite a few places and his English representation deviated factually from the source text and general practice of insurance. Furthermore, it contained quite a few lexical and terminology errors, which were especially unacceptable when made by a native English writer than if they had been made by a Singaporean Chinese. Hence, Student B's translation was marked as the least satisfactory of the three. I must add that I did 'punish' him in comments and marks. But I did it not for his failure to meet my standard, but for his failure to define more appropriate objectives, to live up to them and to use his expertises properly.

\section{Conclusion}

Launching from a Chinese fable about a man cutting his feet to fit a newly bought pair of shoes, this paper has discussed an alternative pedagogical assessment system which has the potential of 'finding the right shoes to fit the feet of an individual'. Named plan-based assessment, this system regards a translation as a plan-guided project and aspires to evaluate the translation by the plan, especially the specific objectives formulated by the translator. This individualised assessment contrasts with conventional assessment systems which all but invariably evaluate the performance of different translators by the same standard. Hence, it is especially useful for translation/interpreting teaching programs at the tertiary level because of its conduciveness to liberal education. 
To explain plan-based assessment, this paper first compared it to other systems, including standard-based and functionally-based assessments. It then provided a brief introduction to how plan-based assessment works, including evaluation of research, objective setting and justification, problem identification, strategies formulation and cost/risk management. The introduction was followed by a discussion of its four distinguishing qualities. They include: attention to the process of translation rather than the result of translation, concern with setting and achieving specific objectives rather than the universal standard, treatment of translation as an economical process rather than pure cross-language representation, and respect for individuality and personalised working styles rather than insistence on standardisation and homogeneity.

The paper then went on to a case study involving the assessment of a translation assignment undertaken by three different students at the University of New South Wales. In the case study I first presented the plans formulated by the students for tackling the assignment and then commented on whether the plans were acted out, especially if the objectives were achieved. I showed that, as a result of plan-based assessment, the translations of two of the students, which would have been given very different scores by standard-based assessment, were awarded about the same marks for achieving the objectives respectively.

I conclude this paper with two observations. Firstly, use of plan-based assessment has proved very effective in my own teaching experiences. I strongly believe that it is a sensible alternative to standard-based assessment or, at least, it can complement the latter. Secondly, as much as it challenges students to 'find their own shoes', it challenges the teacher to be openminded and tolerant of difference, to see students as individuals with different capacities, to view translation not as a matter of equivalence but as a dynamic changing process and, very importantly, to be knowledgeable about different translation objectives and styles. But the challenges have made my teaching an intellectually interesting and empowering experience both for me and for the students.

\section{NOTES}

1. The writing of this article has been informed by not only a review of various translation theories and years of teaching experiences but also extensive interviews on pedagogy in 2002 with Dr Steen Habro and Professor Dominique Thino of l'Ecole Superieure Nationale des Art Decoratif de Paris. I thank them whole-heartedly for their enlightenment. I am also indebted to Professor Hui-wen Chen of Yuntech University of Taiwan for hosting a series of guest lectures at which I had a first chance to articulate some of the ideas which were to form this paper.

2. For example, the undergraduate class that I teach at the University of New South Wales, featured in the case study of this paper, has 29 students speaking different first languages, ageing from 18 to 55, having different religious/political beliefs, and coming from over 6 different countries.

3. For example, of the three Sydney-based universities that teach translation/interpreting, two are accredited by Naati. The third, the University of New South Wales, used to be accredited by Naati too and only had the relationship severed in late 1990s because of irreconcilable differences of requirements and expectations.

4. I have applied game theory to the practice of simultaneous interpreting (Zhong 2005) and to the teaching of translation/interpreting (Zhong 2006) and have found the application a rewarding and empowering experience.

5. Like many of their compatriots, the English and Chinese spoken by Students A and C are usually regarded as distinct language varieties and are different from Australian (or British, American) English and Mandarin Chinese of P.R. China respectively. Especially their Chinese is often perceived as sub-standard not only by Chinese of PR China but also by themselves.

\section{REFERENCES}

Lee-JahnKe, H. (2005): "New Cognitive Approaches in Process-Oriented Translation Training", Meta 50-2, p. 359-377. Munday, J (2001): Introducing Translation Studies: Theories and Applications, Routledge, London and New York. NAATI (1991): Guidelines for Obtaining Approval of a Course in Interpreting/Translation, revised edition, Canberra. NORD, C. (1997): Translating as a Purposeful Activity: Functionalist Approaches Explained, St Jerome, Manchester. Reiss, K. (1989): "Text Types, Translation Types and Translation Assessment", in A. Chesterman, (ed.), Readings in Translation Theory, Finn Lectura, Helsinki, p. 105-115. 
REISS, K. and H. J. VERMEER (1984): Grundlegung einer allgemeinen translationstheorie, Niemeyer, Tübingen.

VermeER, H. J (2000): "Skopos and Commission in Translational Action", in The Translation Studies Reader, L. VENUTI (ed.), Routledge, London and New York, p. 221-32.

ZHong, Y. (2005): "The Second Best Thing: Game Planning for a Mission Impossible or just for Enjoying the Process of the Work", Across Languages and Culture 6-1, p. 91-111.

ZHONG, Y. (2006, to be published): "Let's Talk Translation Economically: A Case Demonstration of Re-Articulating Translation through Economics Jargons ", Across Languages and Culture. 